Meta

Journal des traducteurs

Translators' Journal

\title{
The Rôle of Theory in Translator Training: Some Observations about Syllabus Design
}

\section{Mark Shuttleworth}

Volume 46, numéro 3, septembre 2001

URI : https://id.erudit.org/iderudit/004139ar

DOI : https://doi.org/10.7202/004139ar

Aller au sommaire du numéro

\section{Éditeur(s)}

Les Presses de l'Université de Montréal

ISSN

0026-0452 (imprimé)

1492-1421 (numérique)

Découvrir la revue

Citer cet article

Shuttleworth, M. (2001). The Rôle of Theory in Translator Training: Some Observations about Syllabus Design. Meta, 46(3), 497-506.

https://doi.org/10.7202/004139ar
Résumé de l'article

S'appuyant sur la constante remise en question l'utilité de la théorie en traduction, cet article tente de cerner exactement ce que nous cherchons à accomplir par l'incorporation d'un élément théorique dans les programmes de formation pour traducteurs. On examine ainsi de façon précise les possibilités qu'offrent des cours de théorie générique, dans lesquels on retrouve ensemble des étudiants ayant pour spécialisation une combinaison de deux langues dont une seule commune. Pour que de tels cours soient utiles, il faut adopter un programme assez général qui aborde les questions qui préoccupent les étudiants, qui les laisse se frotter à des opinions diverses, qui fournit une autre solution aux dichotomies conformes à la norme, qui encouragent la formulation de leurs propres stratégies afin de résoudre les problèmes de traduction, qui aide à l'entrée dans le domaine de la traduction, et qui prouve que traduire n'est pas une occupation entièrement $a d$ hoc et subjective. On suggère également qu'il faut harmoniser l'élément théorique officiel avec le contenu même du programme afin que la théorie soit reconnue comme utile à la pratique et ainsi développer une théorie autonome propre qui développera la compétence.
Ce document est protégé par la loi sur le droit d'auteur. L'utilisation des services d'Érudit (y compris la reproduction) est assujettie à sa politique d'utilisation que vous pouvez consulter en ligne.

https://apropos.erudit.org/fr/usagers/politique-dutilisation/ 


\title{
The Rôle of Theory in Translator Training: Some Observations about Syllabus Design'
}

\author{
MARK SHUTTLEWORTH \\ University of Leeds, Leeds, United Kingdom
}

\begin{abstract}
RÉSUMÉ
S'appuyant sur la constante remise en question l'utilité de la théorie en traduction, cet article tente de cerner exactement ce que nous cherchons à accomplir par l'incorporation d'un élément théorique dans les programmes de formation pour traducteurs. On examine ainsi de façon précise les possibilités qu'offrent des cours de théorie générique, dans lesquels on retrouve ensemble des étudiants ayant pour spécialisation une combinaison de deux langues dont une seule commune. Pour que de tels cours soient utiles, il faut adopter un programme assez général qui aborde les questions qui préoccupent les étudiants, qui les laisse se frotter à des opinions diverses, qui fournit une autre solution aux dichotomies conformes à la norme, qui encouragent la formulation de leurs propres stratégies afin de résoudre les problèmes de traduction, qui aide à l'entrée dans le domaine de la traduction, et qui prouve que traduire n'est pas une occupation entièrement ad hoc et subjective. On suggère également qu'il faut harmoniser l'élément théorique officiel avec le contenu même du programme afin que la théorie soit reconnue comme utile à la pratique et ainsi développer une théorie autonome propre qui développera la compétence.
\end{abstract}

\section{ABSTRACT}

"With doubts about the usefulness of translation theory never far from many people's minds, this paper seeks to consider exactly what it is that we are trying to achieve by including a theoretical component in translator training programmes. Within this context the paper specifically examines the possibilities of generic theory courses - in which students who are working with different language pairs and who probably have only a single language in common are all taught together - as opposed to a more languagespecific approach. In order to attain the relevance that they purportedly so often lack, such courses need to set a fairly broad agenda for themselves, seeking if possible to address the type of questions likely to be uppermost in students' minds, expose students to a range of differing opinions on controversial issues, provide an alternative to standard dichotomies, encourage participants to arrive at their own strategies for solving translation problems, prepare students for work within the translation industry and demonstrate that translation is not an activity which is completely ad hoc and subjective. The paper furthermore suggests that every effort should be made to harmonise the formal theory component with everything else that goes on in the programme, so that theory is seen to be relevant to practice. Within this broader perspective one of the main purposes of this training component should therefore be to enable students to develop their own personal, internalised theory which will inform their developing performance as professional translators."

\section{MOTS-CLÉS/KEYWORDS}

generic theory courses, translator's performance, translation theory, translator training programmes 


\section{Introduction}

A recent essay that I found myself assessing contained a surprising yet fascinating statement. Describing the procedures that had been followed by a famous turn-ofthe-century translator who was notable for the fact that he had no first-hand knowledge of the language from which he translated, the student explained that "a medium was employed to assist the translator to understand the English source text." While in my more level-headed moments I am forced to concede that this surprising statement is more likely to be the result of interference from the student's native language than the proposal of shamanistic translation practices it would appear on the face of it to be, I nonetheless find the idea of such a non-standard procedure both intriguing and not entirely inapposite. Perhaps this image does encapsulate something of the mysteries of the translator's art; however, in the absence of a friendly medium we who are involved in translator training have no choice but to struggle to articulate the problems of translation in order to pass on to our students any insights we may gain. In this paper I intend to consider what it is that the theoretical component that is generally included in translator training programmes should be intended to achieve. In the UK nearly all university-based translator training takes the form of one-year MA schemes in translation studies, and it is this constituency to which I shall be addressing my remarks most specifically. Most of the participants in such programmes tend to be recent language graduates who are thinking very seriously about pursuing a career within the translation industry. Typically-at least in the case of graduates of British universities - they will have had a certain amount of experience of translation during their undergraduate studies, although all too frequently this will have been treated as part of the language learning process rather than as a meaningful exposé of the issues faced by professional translators. Many professional translators argue vehemently that translation theory-and even any kind of formal training-is a waste of time (see Baker 1992:3 and Robinson 1997:175-6), and that the best possible preparation that somebody wishing to enter the profession could undergo would be a period working within a professional environment-assuming that the person had the necessary aptitudes and technical background in the first place. After all, translators are supposed to be born, not made-end of story. This is a perception which may well be shared by at least some students undertaking a university training programme. Such students may view the theoretical component as a heart-sink subject, as an academic hoop they are required to jump through on their way to taking up their chosen career, or as a kind of bolton designed to lend a largely vocational programme an air of greater "academic respectability." And if we are not careful, that is just what it can become.

The title of Levy's article "Will Translation Theory be of Use to Translators?" (1965) gives voice to the concern felt by many translation scholars that their work should not get caught up in a spiral of ever-increasing abstraction, but that at least part of it should be of tangible benefit to practising or trainee translators. In line with this aspiration Ingo states that "Translation theory can ... be said to have the same function with regard to the study of interpreting and translation as grammar has with regard to the study of languages" (1992:49). Along similar lines, in a more overtly pedagogical work Baker draws an analogy between translation and the medical profession and argues that the academic training necessary for either will need to 
include "a strong theoretical component" that encourages students to "reflect on what they do, how they do it, and why they do it in one way rather than another" (1992:1-2). In another coursebook-style work, Robinson rejects the suggestion that formal instruction in translation is "worse than useless, counterproductive" by arguing that what goes on in the classroom needs to be made to resemble as closely as possible the type of "inductive" learning which the translator naturally-and unconsciously-undergoes when solving real translation problems (1997:174). However, he displays a healthy cynicism regarding the robustness of many specific theories, and warns that even those which reflect the tensions and compromises characteristic of real-world translation with the highest degree of realism can all too easily "harden into rigidly general patterns," thus moving "from flux to stability, from complexity to simplicity, from flexibility to rigidity" (1997:179). He consequently advocates a shift from static theory to theorizing, an activity which he characterizes as "the complex processes by which a person organizes a group of loosely related insights into a pattern or regularity and ultimately into a rule" (1997:181). In other words, according to Robinson the ultimate aim of such training should be to show participants how to construct their own theories, and ultimately to help them to think more constructively (1997:182).

In parallel with Robinson's distinction, when talking about translation theory we need to differentiate between on the one hand a formal theory-in other words, a series of statements, which together have a "strong power of explanation and prediction" regarding translation (Holmes 1988:93-4), which is first and foremost generally intended as a research tool rather than an aid for the translator-and on the other a body of often conflicting insights which together provide a framework within which a trainee translator can begin to make translation decisions. I suggest that it is definitely the latter that should be of greater interest to us as syllabus designers and teachers of translation theory on vocational translation courses. There is of course the simple fact that some students like to be told there is one "correct" solution to every problem and will be confused if they are presented with a range of possibilities each of which has a degree of validity. However, it also seems to be the case that many students expect such a course to introduce them to a range of important translation theories (see below). Furthermore, translation is a messy, multi-dimensional, largely subjective process, and we do our students no favour if we even implicitly suggest the contrary. Indeed, if a single theory (such as stylistique comparée or German functionalism/skopos theory) is presented without time being given to discuss its weaknesses and to explore alternative rationalizations then sooner or later participants will inevitably become aware of its restrictions, with the result that they may end up rejecting it completely. Another issue-which is sadly beyond the scope of this article-is the metaphors which we choose to describe translation. This is a factor which can have far-reaching consequences for the way we view the nature of translation and the rôle of the translator and so we would do well to choose our words carefully in this respect. ${ }^{2}$

\section{Generic theory courses}

At the University of Leeds where I teach, students doing the one-year MA in Applied Translation Studies are offered two separate theoretical courses. The first, which 
forms a compulsory core course and places the emphasis on practical, professional issues, is an attempt at a course along the lines described above. (Translation theory is a term I actually try to avoid in the context of this course, preferring more euphemistic formulations such as "Methods and Approaches"—which is in fact the title I use.) The second, on the other hand, is intended as a research-oriented course in translation studies which can be taken as an option by those for whom it is of interest; as such it will not concern us in what follows. Besides the UK, students come from a range of countries - above all in Western Europe and East Asia-and receive training in translation in a dozen or so different language combinations. This means that for a number of very practical considerations it is not possible to teach translation theory in close conjunction with a particular language pair. What is offered instead is what might be termed a generic theory course, in which students who are working with different language pairs and who probably have only a single language in common (i.e., English) are all taught together. There is at least one very obvious disadvantage to such an arrangement, which is that it severely restricts the possibility of studying real texts and their translations or of discussing a translation which all the members of the group have done. Indeed, not only is there just a single shared language, but this language will almost certainly be the source language for one section of the group and the target language for the other. However, if handled carefully even such apparently restricting circumstances can be used to engender in students a heightened conceptual awareness of a wide range of problem areas. Indeed, there are plenty of procedures that can be used to make a generic approach into a beneficial experience for participants.

Back-translation can of course be used to provide at least limited access to unknown languages. For instance, when discussing how to translate realia in context, back-translated extracts from a Russian ST can be supplied along with a published English version (with the key item removed):

Russian (back-translation): "For lunch—only soup, for supper—only kasha."

English translation: "Lunch consisted of soup, and only was served for supper."

(Shalamov, trans. John Glad Typhoid Quarantine)

After the students have been told the context (a Stalinist labour camp) and have had a brief explanation of the meaning of kasha (a porridge-like staple of the Russian diet, but one which can be made from a range of different grains, rather than just oats) they are invited to suggest various possible translations (e.g. porridge, gruel, slops, kasha, etc.) and to discuss what might be the pros and cons of each one. Experience has shown that, if given a proper explanation, those who have no Russianthe vast majority-are at no serious disadvantage, while the principles that emerge from discussion can be applied to other language pairs without difficulty.

One approach that such a generic course clearly excludes is a "rule-based" methodology grounded in contrastive linguistics. This type of technique is inevitably tied to a particular language pair, and involves the systematic analysis of the lexical, grammatical and structural incompatibilities between SL and TL. Hönig (1997:6-7) discusses the limitations of such a technique, and I must say that I share his misgivings. As I see it, a major problem with a rule-based approach of this type is that so many potentially problematic areas_-given our present state of linguistic knowledge at any rate-are 
simply out of reach of this type of rule, and so simply tend to be swept under the carpet with a throwaway phrase along the lines that "It doesn't quite work like that in Russian." 3 By contrast, what is called for in the type of course which I am advocating is an approach which is basically text-bound, in which real STs and TTs are studied as examples of translation problems and solutions.

Up to now I have been discussing fairly global questions to do with the overall approach that can usefully be taken to teaching the theoretical component. From this point on, I intend to consider some of the more specific aims that can be envisaged in terms of preparing students for translating careers. In line with this, for most of what remains of this article, I shall argue that in order to attain the relevance that they are so often perceived as lacking, courses in translation theory need to set a fairly broad agenda for themselves, seeking if possible to a) address the type of questions likely to be uppermost in students' minds, b) expose students to a range of differing opinions on controversial issues, $c$ ) provide an alternative to the standard dichotomies according to which translation has all too often been described, d) encourage participants to arrive at their own strategies for solving translation problems, e) prepare students for work within the translation industry and f) demonstrate that translation is not an activity which is completely ad hoc and subjective. I will now consider each of these areas in turn.

\section{a) Addressing students' questions}

What I have to say in this section will be largely based on two sets of feedback which I obtained from MA students during the academic years 1997-8 and 1998-9. The first consisted of the responses to a preparatory questionnaire I distributed in September 1998 to a group of new students about to start the course. The second-logically, if not chronologically - took the form of written answers to the question "What translation problems are uppermost in your mind at this stage?"; these were submitted in November 1997 (i.e., about 6-7 weeks into the previous year's course). The course as taught in the two academic years was substantially the same.

The questionnaire distributed in September 1998 was completely open-ended in that it invited students to answer in their own words the two questions "What do you think the aims of a course on translation theory should be?" and "Do you have any particularly burning questions which you hope it will answer?.” Thirty-one questionnaires were returned out of a possible maximum of 37; for the sake of convenience the answers to the two questions will be considered together.

Three matters in particular were raised more frequently than any other. Firstly, twelve students were keen that the course should focus on a variety of different theories and approaches; amongst these, a number of respondents specifically stated that they wanted to learn about the opinions and ideas of famous theorists or translators. Secondly, twelve people expressed the hope that the course would focus on specific translation problems. Thirdly, people were anxious that the contents of the course should be presented as a theoretical background for their (present or future) practical translation work; this comment was made by eleven respondents.

These seem to have been the three greatest concerns. There were, however, a number of other areas which were mentioned by more than one person. These included the relative merits of different translation methods (five respondents, including one 
return specifically mentioning literal vs. free translation); theory as a purely academic subject, the history of translation, and criticizing translated texts (four each); translation across cultures (three); sets of guidelines for tackling any translation, the conflict between the translator's viewpoint and the client's needs, how to be a good translator, and how to get used to different styles (two each). There were also some twenty comments made by single respondents. These ranged from the highly practical (e.g. "How do you translate nuances and jokes?" or "What tools are available?") to the highly speculative and philosophical (e.g. "Can an exact translation ever exist?" or "What is translation?"). Finally—and by no means insignificantly-one student voiced what was no doubt a more widespread concern by asking "Would it be boring?".

As stated above, the other piece of feedback, received in November 1997, came in the form of a list of problem areas with which students were wanting some guidance. As such it was basically intended-and used-as a wish-list for the following two teaching sessions. Those which were considered most representative were selected from the responses obtained, and were quoted more or less verbatim in the following week's handout, as follows:

1. How much licence is one permitted in translating realia and filling semantic voids?

2. Isn't the Greek translator of the passage from Stephen Hawking's A Brief History of Time (quoted by Mona Baker) taking things a bit too far? ${ }^{4}$

3. How do you translate long involved sentences with lots of clauses?

4. How do you avoid expressing TT in the grammatical structure of SL, since you are always influenced by the ST?

5. Does the translation have to read like an original? If so, how tied are you to the text? How much authority does a translator have? Basically, what are the boundaries between translating and rewriting?

6. Word order: how do you express all the same information fluently without making one part of a clause sound too marked?

Interestingly-and reassuringly for those who are actively involved in research in translation studies - some of these (e.g. numbers four and five) reflect quite closely some of the central concerns of the discipline. However, another message that comes across very clearly from these questions is that the matter of licence and freedom is a major issue for many students in the early stages of a training course. By this stage students will have heard descriptions of how STs were changed significantly during the translation process; this idea often worries them as they are unable to square such radical modification with their own internal conception of what translation should be. Indeed, it is important to recognize the magnitude which such concerns frequently assume for students (particularly during the earlier stages of their programme) and to attempt to build their confidence. In line of this, from the start of the course it makes sense to place a certain amount of emphasis on the following type of question:

- must you translate everything in a text?

- can you add anything?

- can you put an interpretation on the original?

- can you "change the meaning"?

- how "sacred" is the wording?

As students progress through the course, however, the aim is to make them gradually more aware of equally important, but perhaps higher-level, problematic areas (e.g. questions of discourse structure, genre, culture, audience, function and so 
on). It is vitally important that a theoretical course raise such issues, even if students only feel ready to take them fully into account in their own translation practice at a later date.

\section{b) Exposing students to different opinions}

This has already been discussed to some extent in previous sections of this paper. It seems to be a vital part of the process of making students into independent thinkers, so that the possibility of causing some initial confusion is far outweighed by the need to communicate something of the complexity of translation decisions and the fact that there are never completely right or wrong solutions to problems. This is of course more appropriate to some areas than others; translation ethics and the question of rightness and wrongness seem to be two issues where this approach could be particularly suitable. Regarding the latter, Hönig (1997:26-7) discusses a case in which the phrase "the languages of ants and bees" is (mis-)translated by a student into German as "mit den Sprachen von Bienen und Enten" ("or with the languages of bees and ducks"), presumably as a result of interference between English ant and German Ente (duck). Hönig imagines a conversation which might ensue between two lecturers, one of whom wants to penalize the student heavily, while the other argues that "duck," although absent in ST, is just as appropriate in this context as "ant." Although this was not Hönig's main intention in describing this fictitious dialogue, it is an example of the type of material which can give students food for thought about a controversial issue.

Inevitably, this approach is likely to backfire with some students. I am reminded of the comment which one student wrote as feedback at the end of the course: "Still don't know what good translation is."

\section{c) Providing an alternative to standard dichotomies}

Popular notions of translation have for far too long been dominated by simplistic contrasts between the "right" and the "wrong," the "faithful" and the "unfaithful," the "literal" and the "free." As we all know, the simple fact is that in translation no contrast is purely binary, while notions of rightness or wrongness are usually relative rather than absolute. Nowhere is this perhaps such a burning issue as in the area of translation criticism, where the quality of a translation has frequently been judged on the basis of either the smoothness of the language or the number of mistakes which it contains. (Leighton (1991:50-1) describes these two tendencies succinctly and wittily as the "it-reads-smoothly" and the "Gotcha" schools).

One way in which we can help students to see beyond such simplistic contrasts is by breaking them down into the dimensions of which they are composed. For example, the literal/free dichotomy is based on a combination of different criteria which often align in such a way as to make it possible to characterize a given translation in general terms as either "literal" or "free." In reality it is only an occasional translation which one would want to label unequivocally with either of these designations, all things being equal, and indeed for the translator trainer few if any fresh insights can be imparted by means of this familiar and well-worn distinction. However, what does make plenty of sense is to talk about its component factors-matters such as the following: 
- the amount of knowledge that the readers are assumed to have

- the translator's own general or specialist knowledge

- how inventive the translator is (or conversely, to what extent he or she relies on equivalents suggested by a dictionary)

- how idiomatic the translation is

- to what extent cultural items are transplanted into the target culture

- whether the translation contains too much or too little information for the requirements of its readers

It is considerations of this sort that tend to give a translation its particular flavour. These formulations are actually taken from the documentation relating to the Leeds MA's various practical translation courses, and serve as part of the build-up to introducing the criteria which are used to assess students' translations, and which we hope are a fair reflection of the approaches adopted in the theory course.

\section{d) Encouraging participants to create their own problem-solving strategies}

Once launched on their careers as translators our students are going to need a framework within which they will be able to make decisions, whether they concern the best way of translating an item of realia for a specific audience, how to cope when a key ST repetition cannot be reproduced in TT because of an inconvenient instance of TL homonymy, or what the most efficient strategies are for locating unknown terminology. The extent to which our students will be able to think creatively about such problems will depend to a large degree on how far we can cease simply trying to impart a static body of knowledge that students need to assimilate irrespective of whether it proves to be of any lasting value to them, and start to construct our courses in accordance with Robinson's notion of theorizing, an activity which will hopefully prove to be "far more useful to them in their professional and private lives as translators than any specific rules will ever be" (Robinson 1997:181). ${ }^{5}$

\section{e) Preparing students for the translation industry}

It should be stated that this is not perhaps the main job of the theoretical component, nor is that the only or even the most obvious context for this to take place. There are in fact all kinds of ways in which this aim can be achieved within the programme as a whole, and it is ultimately a matter of judgement how far it is to be integrated into the theory course as such. On a highly practical level, professional translators can be invited to talk about the realities of work within the profession. In order to achieve greater up-to-the-minute relevance in the eyes of potential employers, training - preferably hands-on — can be offered in the use of a range of industrystandard translation memory and terminology management systems (in fact in Leeds we have a whole compulsory course devoted to this). In addition, sessions on the principles of simulated knowledge acquisition for the purpose of translating technical texts are an important part of any preparation for work within the industry. Finally, students can be given the chance to practise verbalizing the procedures they perform and the problems they encounter, and in general talking articulately about their work. 


\section{f) Demonstrating that translation is not ad hoc and subjective}

Students might well be tempted to conclude that they have total freedom in how they translate. Rule-based thinking is discouraged, the concepts of right and wrong have been if not abandoned then at least relativized to some extent, while students will for the most part still be in the process of developing their own translational instincts. The truth is of course that translation lies somewhere between the rule-based and the arbitrary, and it is only through skill and experience that the translator will be able to know exactly what is appropriate in any given situation. So we can only provide encouragement to our students as they experiment with different strategies and attempt to make sense of the various theoretical ideas which we introduce them to.

\section{Conclusion}

It should hopefully be apparent from what I have said that I do not believe that the theoretical component should simply be a bolt-on designed to add "academic weight" to a training programme. Rather, every effort should be made to harmonize what is covered there with everything else that goes on in the programme, so that theory is seen to be relevant to practice and this is reflected in-amongst other things - the criteria used for assessing students' translations, the feedback which is given to students, and so on.

In what has preceded I have tried to provide a formal justification for the presence of a theory course within a training programme, and have also made a number of practical suggestions about what it is realistic to expect such a course to achieve. I have throughout tended to concentrate on general approaches rather than the specific content such a course should seek to cover. The list of aims does not claim to be exhaustive, as clearly there are other goals and areas which it may be appropriate to explore. Furthermore, it should be pointed out that the amount of space devoted to each aim is not intended to reflect the relative weightings that they merit.

Throughout the paper I have attempted to convey the idea that theory should not be viewed simply as a static body of knowledge which needs to be imparted, but rather as a means of encouraging informed reflection on the translation process. From this perspective one of the main purposes of this training component should therefore be to enable students to develop personal, internalized methods of theorizing about what they are doing, which will hopefully provide them with a set of techniques to enable them to produce translations of a high standard. So our student who at the start of the paper was unintentionally proposing a translation method which involved the use of supernatural resources was perhaps tapping into something that is not quite so outrageous as might first appear-if, that is, we understand the procedure as a metaphor hinting at the sheer complexity, elusiveness and mystique of what translators are routinely expected to achieve.

\section{NOTES}

1. The present article is a modified and enlarged version of a paper which I gave at the II Jornadas sobre la formación y profesión del traductor e intérprete at the Universidad Europea de Madrid, 17-20 February 1999. It is being published here by permission.

2. Hönig (1995) includes a discussion of the rival "translation as building bridges" and "translation as crossing rivers” metaphors, while Newmark (1981/1988:ix) provides an extended-and entertaining-list of "clichified" images of translation. 
3. Into this category I would, for example, fit the type of semantic associations and figurative extensions that allow you, for instance, to say in English the kettle has boiled but not the corresponding * chainik vskipel in Russian.

4. The reference here is to Baker (1992:31-3), who describes how the Greek version of the passage in question contains a number of radical cultural substitutions.

5. Robinson in fact takes this idea one step further by suggesting that the theories of a number of prominent translation scholars- the fruit of these writers' own theorizing — are a reflection of their authors' particular learning styles (1997:73-80).

\section{REFERENCES}

BAKer, M. (1992) In Other Words: A Coursebook on Translation, London: Routledge.

Holmes, J.S. (1988) "Translation Theory, Translation Theories, Translation Studies, and the Translator," in James S. HoLmes Translated! Papers on Literary Translation and Translation Studies, Amsterdam: Rodopi, 93-98.

HönIG, H.G. (1995) Konstruktives Übersetzen, Tübingen: Stauffenburg.

- (1997) "Positions, Power and Practice: Functionalist Approaches and Translation Quality Assessment," in Current Issues in Language \& Society, 4:1 ("Translation and Quality"), 6-34.

Ingo, R. (1992) "Translation Theory: Four Fundamental Aspects," in Cay Dollerup \& Anne Loddegaard (eds) Teaching Translation and Interpreting: Training, Talent and Experience, Amsterdam \& Philadelphia: John Benjamins Publishing Company, 49-56.

Leighton, L. G. (1991) Two Worlds, One Art: Literary Translation in Russia and America, DeKalb: Northern Illinois University Press.

Levy, J. (1965) "Will Translation Theory be of Use to Translators?", in Rolf Italiaander (ed.) Übersetzen: Vorträge und Beiträge vom Internationalen Kongress literarischer Übersetzer in Hamburg 1965, Frankfurt am Main: Athenäum Verlag, 77-82.

Newmark, P. (1981/1988) Approaches to Translation, Hemel Hempstead: Prentice Hall.

Robinson, D. (1997) Becoming a translator: An Accelerated Course, London \& New York: Routledge.

Shalamov, V. (trans. John Glad) (1995) “Typhoid Quarantine," in V. Erofeyev \& A. Reynolds (eds) The Penguin Book of New Russian Writing, Harmondsworth: Penguin Books, 1-21. 